\title{
Preparation and Characterization of Gelatin-Based Films Cross-Linked by Two Essential Oils at Different Concentrations and Plasticized with Glycerol
}

\author{
Hayet El Kolli \\ Multiphase Polymeric Materials Laboratory \\ University of Ferhat Abbas Setif 1 \\ Setif, Algeria
}

\author{
Meriem El Kolli \\ Laboratory for the Valorization of Biological Natural Resources \\ University of Ferhat Abbas Setif 1 \\ Setif, Algeria
}

\begin{abstract}
Gelatin cross-linking has recently been discovered to be a very appealing production method. The current research looks at various commercial gelatin (type B) films to improve their physical qualities. Bunium alpinum and bunium incrassatum Essential Oils (EOs) in two quantities $(5 \%$ and $25 \%)$ were added to the films, which showed substantial biological activity (antibacterial, antioxidant, antihemolytic, and antiinflammatory). According to electronic scanning microscopy results, the basic gelatin matrix had changed and there were multiple dense spots on the cross-linked films. The particles appear to be more bonded in an isotropic form. Infrared spectroscopy cannot provide substantial accuracy on the new characteristics and chemical interactions formed due to the complex system of gelatin and EOs. According to the UV transmission test results, adding EOs to gelatin films improves the barrier properties against UV rays and prevents UV light transmission. Finally, the swelling water test revealed that included EOs in the film composition reduce the film's swelling.
\end{abstract}

Keywords-gelatin; bunium alpinum; bunium incrassatum; crosslinking; barrier property against $U V$; food packaging

\section{INTRODUCTION}

Polymeric materials are required in a variety of routine applications, from food packaging to cosmetics and other specialized sectors, e.g. the biopharmaceutical and pharmaceutical sectors [1]. For more than 20 years researchers try to improve conventional polymers by adding particles into the polymer matrix, thus changing its properties [2]. The agriculture and food sectors are increasingly concerned about the preservation of commonly consumed items against deterioration caused by environmental (heat, sunlight) or biological (bacterial and fungal) factors [3]. Bio-packaging is currently being researched as a healthy and environmentally friendly option [4]. Traditional polymers used in the product packaging are being replaced with healthier, less toxic and biodegradable alternatives in the agri-food, pharmaceutical, and cosmetic industries through technological procedures. As a result, biopolymers like gelatin are gaining popularity in this sector. Film-making gelatin is a form of gelatin. It becomes more stable and manageable when mixed with other substances [5]. In innovative packaging applications, biopolymers are coupled with natural products such as medical plant extracts (essential oils and plant powders) and pure or semi-purified natural components (polyphenols, flavonoids, pigments, etc.) [6]. This link bestows all of the qualities and benefits associated with natural items on the designed bundle. The use of essential oils in packaging systems, imparts the flavors of the essential oils used and the antibacterial and antifungal properties that characterize them [3, 7]. Phenolic compounds protect packaged commodities from degradation caused by external conditions and bacteria by acting as antioxidants [8].

This study aims to develop a novel type of gelatin packaging that is cross-linked with glycerol. This polymer contains antibacterial, antifungal, and antioxidant Essential Oils (EOs) from bunium incrassatum and bunium alpinum [9].

\section{MATHERIALS AND METHODS}

\section{A. Chemicals}

Hydro-distillation in a Clevenger-style device was used to extract the volatile EOs, and each separated oil was kept at $4^{\circ} \mathrm{C}$ in a refrigerator. The EOs were analyzed using Gas Chromatography-Mass Spectrometry (GC-MS). The contents of the EOs were determined by comparing the mass spectral pattern and Retention Indices (RIs) of the EOs to those of pure compounds available in the literature as well as a laboratorybuilt database of authentic chemicals [10]. Fluka and Biochemika synthetized gelatin powder from porcine skin (with a medium gel strength 180 blooms) was utilized.

\section{B. Preparation of Biofilms}

The methodology defined in [11] is employed in this work with minor modifications. To make the film-forming solution, $3.5 \mathrm{~g}$ gelatin powder ( 180 bloom porcine skin gelatin) was mixed with $100 \mathrm{ml}$ distilled water for $30 \mathrm{~min}$, then $2 \mathrm{ml}$ glycerol (plasticizer) were added. This mixture was heated at $70^{\circ} \mathrm{C}$ for $30 \mathrm{~min}$ and was constantly stirred. At the same time, a 3:1 (v/v) mixture of EOs and Tween-20 (emulsifier) was prepared. The 
combination was added to the initial solution in percentages of $5 \%$ and $25 \%$. A vortex mixer (3500rpm) was used to homogenize the generated solution for $3 \mathrm{~min}$. The dissolved air in the films was then extracted with a vacuum pump. Finally, $13 \mathrm{ml}$ of liquid were placed in plastic Petri dishes and were allowed to air dry for 4 days at room temperature. The films were then carefully peeled and assessed. Control films were made using the same procedure as the test films but without the EOs.

\section{Characterization}

\section{- Thickness}

In compliance with the French standard NF Q 03-016, the film thickness (e) was measured with a foot electronic slidetype Mitutoyo DIGIMATIC 500-123U. Three discs were cut from each formulation (each measuring $4.5 \mathrm{~cm}$ ). Each disc was measured for thickness in 5 different spots at random [12].

\section{- Areal density}

The film's mass determines the areal density in $\mathrm{g} / \mathrm{m}^{2}$ based on a unit area. The French standard NF Q 03-019 was used to determine it. Each formulation was sliced into 3 discs (each measuring $4.5 \mathrm{~cm}$ ) and was weighed precisely. The film density (D) was calculated using the equation $\mathrm{D}=\mathrm{AD} / \mathrm{e}$ from the thickness and basis weight [13].

\section{- Scanning Electronic Microscopy (SEM)}

SEM was used to evaluate sample films' morphology or surface topography (a JEOL JSM 6360LV scanning electron microscope was utilized). To make them conductive a 25 to $30 \mathrm{~nm}$ thickness layer was placed to the surface and the samples were first metalized with gold in a Cressington Sputter Coater metallizer. Electron acceleration voltages ranging from 3 to $10 \mathrm{kV}$ were used to obtain the photos [12].

\section{- Fourier Transform-Infrared (FT-IR)}

Infrared spectroscopy was used to determine the physical states of organic and inorganic molecules based on their vibrational properties. Chemical bonds do vibrate in specific modes as a result of infrared light (deformation, stretching). As a result, comparing the sample's incidence and transmission is sufficient to disclose the sample's fundamental chemical functions [14]. The FTIR-8400S device was used (Fourier Transform Infra-Red Spectrophotometer, SHIMADZU). The data were read using IR-SOLUTION software.

\section{- Transparency and light transmission}

The film's light transmission in ultraviolet and visible light was measured using a UV-visible spectrophotometer (UNICAM UV 300 type 200-800nm). VISION32 Software V1.10 was used to read the data. The film's Transparency Value (TV) is calculated by [14]:

$$
T V=\log \left(T_{600}\right) / e
$$

where $T_{600}: 600 \mathrm{~nm}$ transmission fraction, $e$ : the thickness of the film (mm).

A high $T V$ value is indicative of low film transparency.

\section{- Swelling test}

The film samples $(40 \mathrm{~mm} / 30 \mathrm{~mm})$ were dried for $24 \mathrm{~h}$ at $104^{\circ} \mathrm{C}$ in an air-circulating oven until they were consistent in weight. The initial weight $\left(W_{i}\right)$ was measured. The film samples were immersed in a $100 \mathrm{ml}$ Erlenmeyer flask with $50 \mathrm{~mL}$ distilled water for $24 \mathrm{~h}$ at room temperature. After removing from the flask and rubbing it between filter papers to remove any residual surface water, each sample was weighed and the ultimate weight $\left(W_{f}\right)$ was calculated. Equation (2) [15] was used to compute the weight gain or swelling percentage (S \%):

$$
S(\%)=\left(-W_{f} / W_{i}\right) 100
$$

At least three measurements were taken in each test.

\section{RESULTS AND DISCUSSION}

This is a new line of research which aims to synthesize biodegradable matrices, based on gelatin or another biopolymer, with new formulations by adding safe to use and low cost natural metabolites such as EOs, known for their broad antimicrobial spectrum with the aim of using them in packaging, as patches for the release of drugs, or in the case of the encapsulation of active ingredients. Table I shows the thickness, areal density, and density of the several gelatin films supplemented with varying concentrations of EOs, as well as the control film.

\section{- Training films}

The chains of gelatin unfold during the solubilization of gelatin in water, generating the polymer network. The viscosity of the film-forming fluids increases substantially as the gelatin molecules flocculate and transform into a gel at temperatures above the gelling temperature $\left(60^{\circ} \mathrm{C}\right)$. Reduced hydration layers around polymer chains increase hydrophobic interactions, resulting in increased hydrophobic interactions [16]. Gelatin's methyl groups interact with the molecules around them, forming intermolecular connections. The hydrogen-type intermolecular bonds are formed by isolating the hydration solvent (water) from the polymer chains. Glycerol is a low-molecular-weight $(92 \mathrm{~g} / \mathrm{mol})$ hydrophilic molecule that can readily be placed between gelatin segments. Hydrogen bonds arise between the hydroxyl groups of the glycerol and gelatin during the gelling or evaporation of the solvent.

\section{- Look and Flexibility}

Control films and films with EOs and have a smooth, continuous appearance with no surface imperfections. It is worth noting that the flexibility of the films is proportional to the amount of EO used $[16,12]$. The film that contained the most bunium incrassatum EO (25\%) was the most flexible and yellow-tinted (since this EO is darker than the other). Based on this finding, the films developed a stable emulsion system. There is no emulsion breakdown or change during the dehydration process, and no bubbles or cracks appear.

- Thickness

The EO-enhanced films were all thicker in consistency than 
the control film $(0.22 \mathrm{~mm})$. Droplets of EOs can be incorporated into the film network, obstructing the link between gelatin chains, lowering network compactness, and obstructing orderly alignment. The formation of gelatin chains might increase density. This can be controlled by surface tension and/or changes in the size of the oil droplets. Furthermore, EOs are available in various formulations, each of which interacts with the gelatin chain in the film matrix in a distinct way [10]. As a result, the gelatin molecules' arrangement in the film matrix can shift, resulting in changes in film thickness [17]. As a consequence, adding glycerol to the control film enhanced dramatically the surface density. Combining glycerol and EOs increases the film thickness, but has a significant impact on the density. This is because glycerol has a density of only $1257 \mathrm{~kg} \mathrm{~m}^{-3}$.

TABLE I. THICKNESS, AREAL DENSITY, AND VOLUME MASS OF THE FILMS

\begin{tabular}{|c|c|c|c|}
\hline Sample & $\begin{array}{c}\text { Thickness } \\
(\mathbf{m m})\end{array}$ & $\begin{array}{c}\text { Areal } \\
\mathbf{d e n s i t y} \\
\left(\mathbf{g ~ m}^{-2}\right)\end{array}$ & $\begin{array}{c}\text { Volume } \\
\mathbf{m a s s} \\
\left(\mathbf{k g ~ m}^{-3}\right)\end{array}$ \\
\hline Control & $0.22 \pm 0.004$ & 72.705 & 3304.802 \\
\hline $\begin{array}{c}\text { Film with 25\% of } \\
\text { bunium incrassatum }\end{array}$ & $0.36 \pm 0.005$ & 70.651 & 1962.547 \\
\hline $\begin{array}{c}\text { Film with 25\% of } \\
\text { bunium alpinum }\end{array}$ & $0.32 \pm 0.008$ & 64.846 & 2026.441 \\
\hline $\begin{array}{c}\text { Film with 5\% of } \\
\text { bunium incrassatum }\end{array}$ & $0.34 \pm 0.005$ & 69.268 & 2037.306 \\
\hline $\begin{array}{c}\text { Film with 5\% of } \\
\text { bunium alpinum }\end{array}$ & $0.24 \pm 0.008$ & 63.861 & 2660.878 \\
\hline
\end{tabular}

- SEM and determination of the morphology

According to SEM, the control film has a smooth, continuous, compact, and completely transparent surface (Figure 1). For films having varying concentrations of EOs, several dense zones develop on the same sample, where the particles appear more bound with anisotropic structure, without pores, and without micro-fractures (Figure 1). The most densely built-up areas are those with the highest percentage of EOs, meaning that EOs' droplets modify the transverse distribution of protein-protein inside the film matrix (improving roughness), most likely within the film network. Because of the EO droplets, water molecules will not travel through the film network [18]. Terpene compounds make up many EO compositions $[29,20]$. These molecules can combine with different proteins or amino acids in gelatin to form "Protein Cross-links," which change the gelatin's underlying matrix and give rise to various morphologies [21].

\section{- FT-IR}

The FTIR spectra of gelatin and gelatin / EO films are shown in Figures 2 and 3. The purpose of this classification was to determine how various functional groups interacted with each another. Because each film has a large number of functional groups, the FTIR spectra generated from each film include a large number of overlapping absorption bands, offering more information than all of the chemical components analyzed independently. The distinction was made using proteins and polypeptides, which are the essential components that determine function in food systems. The infrared spectra of nearby peptide groups are affected by vibrational coupling.
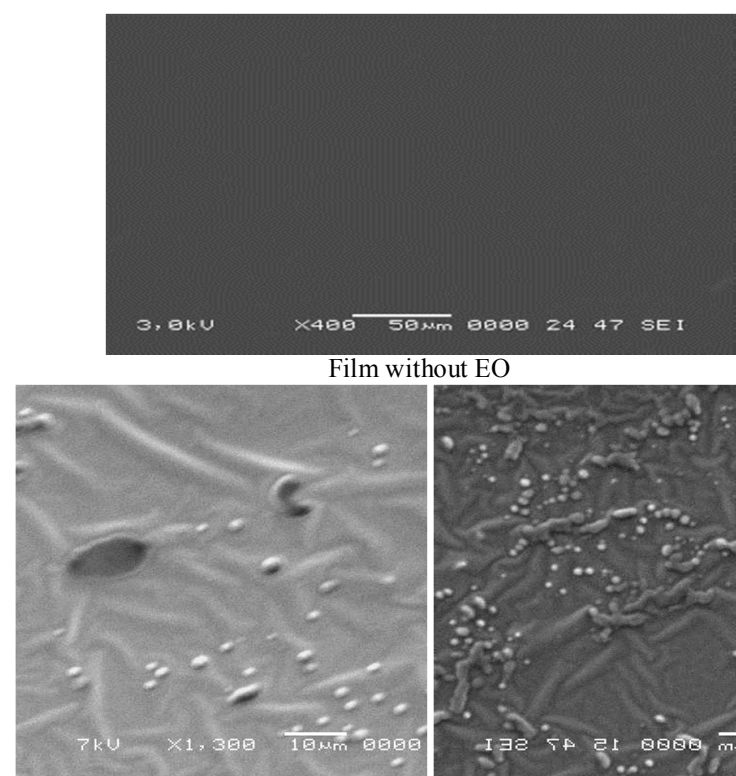

Film enriched with $5 \%$ of bunium incrassatum

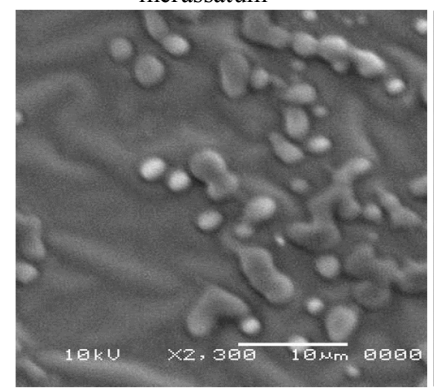

Film enriched with $5 \%$ of bunium alpinuum

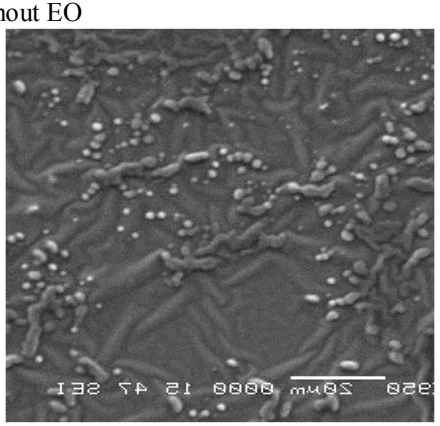

Film enriched with $25 \%$ of bunium incrassatuum

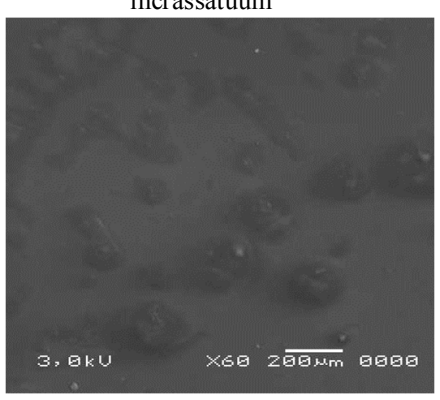

Film enriched with $25 \%$ of bunium alpinuum

Fig. 1. SEM micrographs of the gelatin and gelatin/EO films.

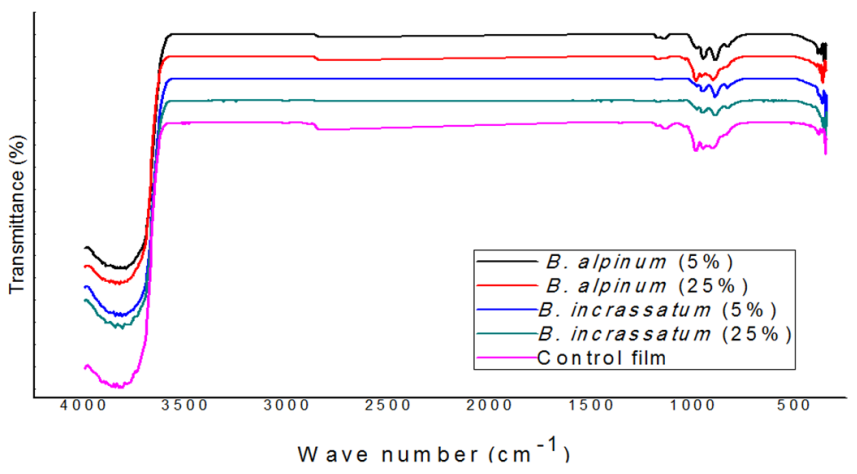

Fig. 2. FT-IR spectra of gelatin films with bunium alpinum and bunium incrassatum EOs at various concentrations $\left(4000-500 \mathrm{~cm}^{-1}\right)$

The vibratory features of FT-IR can be used to show the presence of species adsorbed and/or grafted to the surface of the film. FT-IR does not provide considerable precision on the features and newly developed connections due to the various activities of gelatin and EO, and glycerol in all films [12]. The same prominent peaks with various amplitudes appeared in all FT-IR spectra (Figure 2). 


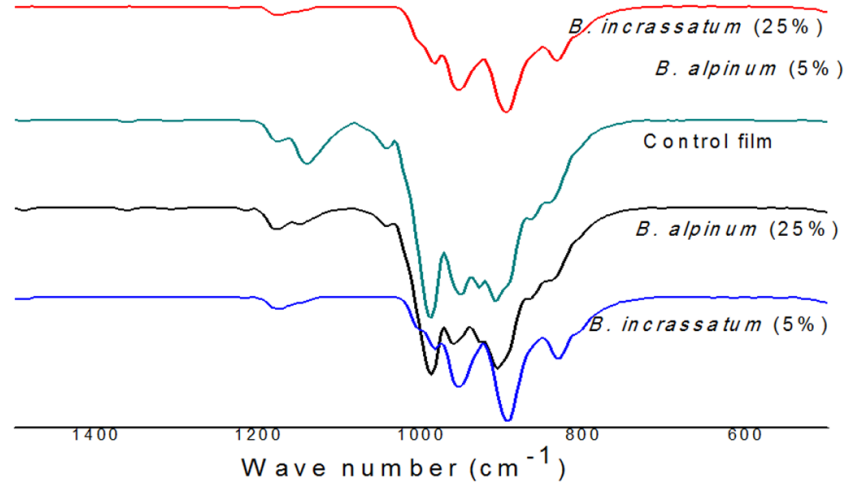

Fig. 3. FT-IR spectra of control and modified films with EOs (1500$500 \mathrm{~cm}^{-1}$ )

The notable peaks in both films with and without EOs were nearly identical: both film samples contained a band with a wavenumber of $1165.32 \mathrm{~cm}^{-1}$. It refers to an amine having a short $\mathrm{C}-\mathrm{N}$ chain that can be used as a primary, secondary, or tertiary amine [12]. Several bands in the $1940-1847 \mathrm{~cm}^{-1}$ range are also found in gelatin and EOs and are linked to $\mathrm{NH}_{2}$ bending vibrations and $\mathrm{C}=\mathrm{O}, \mathrm{C}=\mathrm{C}$, and $\mathrm{C}=\mathrm{N}$ stretching vibrations. At $3826 \mathrm{~cm}^{-1}$, an amide- $\mathrm{A}$ band and an amide- $\mathrm{B}$ band with NH-stretching combined with hydrogen-bonding and $\mathrm{CH}$ stretching were identified.

\section{- Transparency and light transmission}

The spectrum in Figure 4 depicts the transmittance of UV rays and visible light in the wavelength range of 200-800nm of gelatin films enhanced with various EOs. There was no UV transmission in any of the films at $200 \mathrm{~nm}$, including control. They had all started transmitting light at wavelengths less than $300 \mathrm{~nm}$. The use of EOs in gelatin films has been suggested as a means to improve UV barrier properties. These coatings effectively reduce UV light transmission. It can generally bind excellent UV barrier qualities and absorb UV radiation because of the rich amino acid content that produces the amino acids' gelatin and interactions with the EO's diverse components [22, 16]. The control film transmission ranged from 52, 61 to 86 , and $51 \%$ for visible light (300-800nm). The lowest values were seen in the films enriched with EOs (independent of EO type but proportionate to their concentration) (Table II).

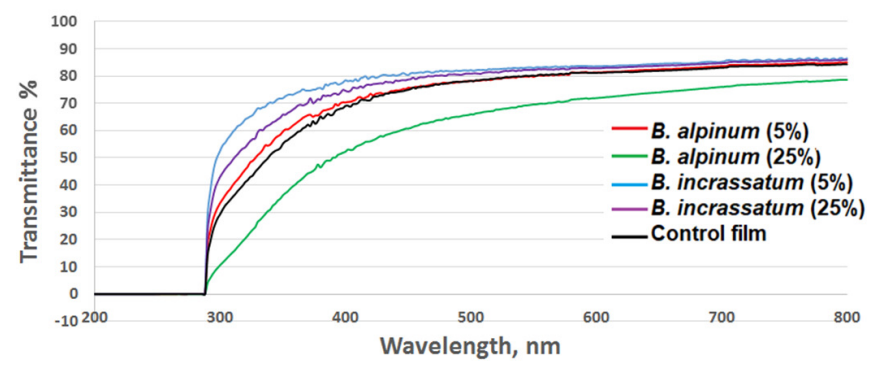

Fig. 4. Transmittance of films at 200-800nm wavelengths.

These data suggest that adding EOs to the films lowered light transmission considerably. The EO droplets in the matrix may be able to block UV and visible light from going through. In the visible range, the film containing $25 \%$ EO of $\mathrm{B}$. incrassatum had the lowest light transmission (from 10.65 to $78.64 \%$ ), followed by the film containing the same proportion of EO of bunium alpinum. The film with $5 \%$ of the EO of bunium incrassatum comes third, whereas the film with $5 \%$ of bunium alpinum comes fourth. The presence of EOs in the films might cause light scattering in variable degrees. For light transmission through the films, the arrangement or alignment of the polymer chains in the film network is crucial. When considering the maximum transparency, the lowest transmittance value is employed [23]. Authors in [24] demonstrated their hypothesis by using lemon EO to lower the opacity of chitosan films. They discovered that the size and placement of EO droplets in the film network can influence the occurrence of this event. The findings in [25] are consistent with this discovery.

TABLE II. TRANSPARENCY VALUES OF THE FILMS

\begin{tabular}{|c|c|c|c|c|c|c|c|c|c|c|}
\hline Glycerol (\%) & EO & \multicolumn{6}{|c|}{ Light transmission (\%) at different wavelengths } & Transparency value \\
\hline \multirow{3}{*}{$20 \%$} & & $\mathbf{2 0 0}$ & $\mathbf{3 0 0}$ & $\mathbf{3 5 0}$ & $\mathbf{4 0 0}$ & $\mathbf{5 0 0}$ & $\mathbf{6 0 0}$ & $\mathbf{7 0 0}$ & $\mathbf{8 0 0}$ & \\
\cline { 2 - 12 } & Control & 0 & 52.617 & 71.836 & 78.456 & 82.189 & 83.635 & 85.26 & 86.513 & 3.579 \\
\cline { 2 - 11 } & Bunium incrassatum 25\% & 0 & 10.651 & 36.241 & 52.243 & 65.958 & 71.917 & 76.027 & 78.645 & 3.300 \\
\cline { 2 - 11 } & Bunium incrassatum 5\% & 0 & 33.435 & 59.623 & 70.344 & 78.329 & 81.302 & 83.582 & 85.003 & 3.378 \\
\cline { 2 - 10 } & Bunium alpinum 25\% & 0 & 29.315 & 55.122 & 69.077 & 78.231 & 81.163 & 83.052 & 84.304 & 3.404 \\
\cline { 2 - 10 } & Bunium alpinum 5\% & 0 & 43.050 & 65.850 & 74.586 & 80.858 & 82.887 & 84.718 & 85.911 & 3.538 \\
\hline
\end{tabular}

\section{- Swelling test}

When EOs were introduced, the swelling of gelatin films was considerably reduced (Table III). Gelatin is a hydrophilic substance, which means it soaks up water molecules. Porous gelatin films have a higher swelling capacity due to their network architecture, allowing more water to pass. Because EOs are hydrophobic, it is possible that adding them to gelatin films reduces their swelling potential. Hydrophobic contact between gelatin's hydrophobic domains and EOs improves the interfacial interaction between matrix (gelatin) and filler (EOs) [26]. This causes the EOs to saturate the gelatin network, preventing water molecules from migrating into the gelatin and reducing swelling [27]. These findings show that gelatin sheets containing EOs could be promising liquid-absorbing packaging materials.

TABLE III. SWELLING VALUES

\begin{tabular}{|c|c|}
\hline Sample & Swelling (\%) \\
\hline Control & $542 \pm 7$ \\
\hline Film with 5\% of bunium alpinum & $530 \pm 3$ \\
\hline Film with 5\% of bunium incrassatum & $547 \pm 3$ \\
\hline Film with 25\% of bunium alpinum & $527 \pm 12$ \\
\hline Film with 25\% of bunium incrassatum & $512 \pm 4$ \\
\hline
\end{tabular}




\section{CONCLUSION}

Plastic packaging has many drawbacks, one of which being its negative influence on the environment. Biodegradable films and coatings made from natural bio-based polymers can be promoted as a viable plastic substitute. In the current study, the EOs of bunium alpinum and bunium incrassatum were shown to be very compatible with gelatin, resulting in flexible and easy-to-handle films in the studied concentration range. Including EOs in the gelatin films resulted in a significant reduction in edema, depending on the dose. According to the SEM results, the EOs were well dispersed in the film matrix, and good adhesion was attained. The addition of EOs to gelatin films on a dose-by-dose basis has improved the UV barrier qualities of gelatin/EO films. These findings suggest that the selected EOs could be helpful as cross-linking agents in several applications, such as food packaging and pharmaceuticals. More research and applications are required to complete the assessment of possible applications.

\section{ACKNOWLEDGMENT}

The authors acknowledge the help in SEM technique of Doctor Abdelyamine Bouda from CDTA (Centre de Développement des Technologies Avancées), Algeria.

\section{REFERENCES}

[1] J. Wroblewska-Krepsztul, T. Rydzkowski, I. Michalska-Pozoga, and V. K. Thakur, "Biopolymers for Biomedical and Pharmaceutical Applications: Recent Advances and Overview of Alginate Electrospinning," Nanomaterials, vol. 9, no. 3, Mar. 2019, Art. no. 404, https://doi.org/10.3390/nano9030404.

[2] M. Danikas, A. Bairaktari, R. Sarathi, and A. B. B. A. Ghani, "A Review of Two Nanocomposite Insulating Materials Models: Lewis' Contribution in the Development of the Models, their Differences, their Similarities and Future Challenges," Engineering, Technology \& Applied Science Research, vol. 4, no. 3, pp. 636-643, Jun. 2014, https://doi.org/10.48084/etasr.441.

[3] K. Oudjedi, S. Manso, C. Nerin, N. Hassissen, and F. Zaidi, "New active antioxidant multilayer food packaging films containing Algerian Sage and Bay leaves extracts and their application for oxidative stability of fried potatoes," Food Control, vol. 98, pp. 216-226, Apr. 2019, https://doi.org/10.1016/j.foodcont.2018.11.018.

[4] E. Basiak, A. Lenart, and F. Debeaufort, "How Glycerol and Water Contents Affect the Structural and Functional Properties of Starch-Based Edible Films," Polymers, vol. 10, no. 4, Apr. 2018, Art. no. 412, https://doi.org/10.3390/polym10040412.

[5] M. C. Gomez-Guillen, J. Turnay, M. D. Fernandez-Diaz, N. Ulmo, M. A. Lizarbe, and P. Montero, "Structural and physical properties of gelatin extracted from different marine species: a comparative study," Food Hydrocolloids, vol. 16, no. 1, pp. 25-34, Jan. 2002, https://doi.org/ 10.1016/S0268-005X(01)00035-2.

[6] D. Carrizo, G. Taborda, C. Nerin, and O. Bosetti, "Extension of shelf life of two fatty foods using a new antioxidant multilayer packaging containing green tea extract," Innovative Food Science \& Emerging Technologies, vol. 33, pp. 534-541, Feb. 2016, https://doi.org/ 10.1016/j.ifset.2015.10.018.

[7] M. Carpena, B. Nunez-Estevez, A. Soria-Lopez, P. Garcia-Oliveira, and M. A. Prieto, "Essential Oils and Their Application on Active Packaging Systems: A Review," Resources, vol. 10, no. 1, Jan. 2021, Art. no. 7, https://doi.org/10.3390/resources10010007.

[8] D. Carrizo, G. Gullo, O. Bosetti, and C. Nerin, "Development of an active food packaging system with antioxidant properties based on green tea extract," Food Additives \& Contaminants: Part A, vol. 31, no. 3, pp. 364-373, Mar. 2014, https://doi.org/10.1080/19440049.2013.869361.
[9] C. Pena, G. Mondragon, I. Algar, I. Mondragon, J. Martucci, and R. Ruseckaite, "Gelatin Films: Renewable Resource for Food Packaging," in Gelatin: Production, Applications and Health Implications, New York, NY, USA: Nova Science, 2013, pp. 71-86.

[10] E. K. Hayet, L. Hocine, and E. K. Meriem, "Chemical Composition And Biological Activities Of The Essential Oils And The Methanolic Extracts Of Bunium Incrassatum And Bunium Alpinum From Algeria," Journal of the Chilean Chemical Society, vol. 62, no. 1, pp. 3335-3341, Mar. 2017, https://doi.org/10.4067/S0717-97072017000100006.

[11] P. Tongnuanchan, S. Benjakul, and T. Prodpran, "Properties and antioxidant activity of fish skin gelatin film incorporated with citrus essential oils," Food Chemistry, vol. 134, no. 3, pp. 1571-1579, Oct. 2012, https://doi.org/10.1016/j.foodchem.2012.03.094.

[12] J. Wu, X. Sun, X. Guo, S. Ge, and Q. Zhang, "Physicochemical properties, antimicrobial activity and oil release of fish gelatin films incorporated with cinnamon essential oil," Aquaculture and Fisheries, vol. 2, no. 4, pp. 185-192, Jul. 2017, https://doi.org/10.1016/ j.aaf.2017.06.004.

[13] L. Scartazzini et al., "Gelatin edible coatings with mint essential oil (Mentha arvensis): film characterization and antifungal properties," Journal of Food Science and Technology, vol. 56, no. 9, pp. 4045-4056, Sep. 2019, https://doi.org/10.1007/s13197-019-03873-9.

[14] P. Tongnuanchan, S. Benjakul, and T. Prodpran, "Comparative studies on properties and antioxidative activity of fish skin gelatin films incorporated with essential oils from various sources," International Aquatic Research, vol. 6, no. 2, Jul. 2014, Art. no. 62, https://doi.org/ 10.1007/s40071-014-0062-x.

[15] G. Kavoosi, A. Rahmatollahi, S. Mohammad Mahdi Dadfar, and A. Mohammadi Purfard, "Effects of essential oil on the water binding capacity, physico-mechanical properties, antioxidant and antibacterial activity of gelatin films," LWT - Food Science and Technology, vol. 57, no. 2, pp. 556-561, Jul. 2014, https://doi.org/10.1016/j.lwt.2014.02.008.

[16] M. Aitboulahsen et al., "Gelatin/pectin-based film incorporated with essential oils: Functional characteristics and shelf life extension of tilapia fillets under refrigeration," Journal of Food Safety, vol. 40, no. 3, 2020, Art. no. e12774, https://doi.org/10.1111/jfs.12774.

[17] J. Xiao et al., "Impact of melting point of palm oil on mechanical and water barrier properties of gelatin-palm oil emulsion film," Food Hydrocolloids, vol. 60, pp. 243-251, Oct. 2016, https://doi.org/ 10.1016/j.foodhyd.2016.03.042.

[18] S. Jahani, A. Shakiba, and L. Jahani, "Fabrication of Gelatin NanoCapsules Incorporate Ferula assa-foetida Essential Oil With Antibacterial and Antioxidant," Zahedan Journal of Research in Medical Sciences, vol. 17, no. 7, Jul. 2015, Art. no. e1018, https://doi.org/10.17795/zjrms1018.

[19] J. Bruneton, Pharmacognosie: Phytochimie, plantes medicinales, $3 \mathrm{rd} \mathrm{ed}$ Paris, France: Technique et Documentation Lavoisier, 1999.

[20] S. Burt, "Essential oils: their antibacterial properties and potential applications in foods - a review," International Journal of Food Microbiology, vol. 94, no. 3, pp. 223-253, Aug. 2004, https://doi.org/ 10.1016/j.ijfoodmicro.2004.03.022.

[21] S. D. Sarkar, B. L. Farrugia, T. R. Dargaville, and S. Dhara, "Physicochemical/biological properties of tripolyphosphate cross-linked chitosan based nanofibers," Materials Science and Engineering: $C$, vol. 33, no. 3, pp. 1446-1454, Apr. 2013, https://doi.org/10.1016/j.msec.2012.12.066.

[22] A. Jongjareonrak, S. Benjakul, W. Visessanguan, T. Prodpran, and M. Tanaka, "Characterization of edible films from skin gelatin of brownstripe red snapper and bigeye snapper," Food Hydrocolloids, vol. 20, no. 4, pp. 492-501, Jun. 2006, https://doi.org/10.1016/ j.foodhyd.2005.04.007.

[23] M. Cofelice, F. Cuomo, and A. Chiralt, "Alginate Films Encapsulating Lemongrass Essential Oil as Affected by Spray Calcium Application," Colloids and Interfaces, vol. 3, no. 3, Sep. 2019, Art. no. 58, https://doi.org/10.3390/colloids3030058.

[24] Y. Peng and Y. Li, "Combined effects of two kinds of essential oils on physical, mechanical and structural properties of chitosan films," Food Hydrocolloids, vol. 36, pp. 287-293, May 2014, https://doi.org/10.1016/ j.foodhyd.2013.10.013. 
[25] S. Shojaee-Aliabadi et al., "Characterization of antioxidant-antimicrobial $\kappa$-carrageenan films containing Satureja hortensis essential oil," International Journal of Biological Macromolecules, vol. 52, pp. 116124, Jan. 2013, https://doi.org/10.1016/j.ijbiomac.2012.08.026.

[26] Y.-H. Hong, G.-O. Lim, and K. B. Song, "Physical Properties of Gelidium corneum-Gelatin Blend Films Containing Grapefruit Seed Extract or Green Tea Extract and Its Application in the Packaging of Pork Loins," Journal of Food Science, vol. 74, no. 1, pp. C6-C10, 2009, https://doi.org/10.1111/j.1750-3841.2008.00987.x.

[27] S. Chaoui, D. Smail, A. Hellati, and D. Benachour, "Effect of Starch Nanocrystals on the Properties of Low Density Polyethylene/ Thermoplastic Starch Blends," Engineering, Technology \& Applied Science Research, vol. 10, no. 4, pp. 5875-5881, Aug. 2020, https://doi.org/10.48084/etasr.3608. 